\title{
Uma Abordagem sobre os Relacionamentos Amorosos e o Adoecimento Psíquico: Relato de Experiência
}

\author{
José Adelmo Da Silva Filho, Lumara Alves Moreira, Maria do Livramento Alencar de Holanda
}

\begin{abstract}
Resumo: A partir da vivência clínica na Saúde Mental de Iguatu-CE, este relato de experiência traz questões advindas dos usuários no set terapêutico sobre relacionamentos amorosos e o adoecimento psíquico. Após apreciação das versões de sentido dos atendimentos e em consonância com teóricos dessa temática examina os efeitos dessas relações e a relevância na dimensão dos afetos. Não se busca fazer análise individual dos casos e suas singularidades, mas sim descrever as percepções sucedidas da experiência de acompanhar a essa demanda de forma geral. Neste relato não se busca defender paradigmas epistemológicos, mas oferecer ampla visão em diversos campos teóricos para enriquecer a temática apresentada e reafirmar que não se trata de suposição de determinada prática profissional, mas um olhar integral ao sujeito a partir da experiência. Com este trabalho foram inclusas discussões sobre a temática dentro dos serviços de saúde mental, vista sua capacidade de ressignificar as práticas profissionais, construir novos saberes, aperfeiçoando os já existentes e adaptando às particularidades de cada um.
\end{abstract}

Palavras-chave: Saúde Mental. Psicoterapia. Experiência.

\section{An Approach on Loving Relationships and Psychic Illness: Experience Report}

\begin{abstract}
Based on the clinical experience at The Mental Health Clinic in Iguatu, this experience report brings questions arising from users on the therapeutic set about love relationships and psychic illness. After appreciation of the meaningful versions of the consultations and in agreement with theorists of this thematic examines the effects of these relations and the relevance in the dimension of affections. We do not seek to make individual analysis of cases and their singularities, but rather to describe the perceptions of the experience of following this demand in general. This report does not seek to defend epistemological paradigms, but offer a broad vision in various theoretical fields to enrich the theme presented and reaffirm that it is not a question of assumption of a certain professional practice, but an integral view of the subject from experience. This work has included discussions on the subject within mental health services, given its capacity to re-signify professional practices, to build new knowledge, to improve existing ones and to adapt to the particularities of each one.
\end{abstract}

Keywords: Mental Health. Psychotherapy. Experience.

\footnotetext{
${ }^{1}$ Enfermeiro. Esp. em Saúde Mental. Residente em Saúde Mental Coletiva pela Escola de Saúde Pública/CE. Contato: adelmof12@gmail.com;

${ }^{2}$ Psicóloga; Especialista na modalidade de residência em Saúde Mental Coletiva pela Escola de Saúde Pública do Ceará; Profissional efetiva da equipe do CAPS III de Iguatu-CE, e demais serviços da rede de Saúde Mental do citado município. Contato: lumara.lumi@gmail.com;

${ }^{3}$ Assistente Social; Mestra em Ensino na Saúde; preceptora da Residência Integrada em Saúde pela Escola de Saúde Pública do Ceará. Contato: liliholanda@uol.com.br
} 


\section{Introdução}

"Relacionamento é o assunto mais quente do momento, e aparentemente o único jogo que vale a pena, apesar de seus óbvios riscos” (BAUMAN, 2003).

Desde as eras mais antigas os filósofos já debatiam questões inerentes à inevitável condição de sociabilidade do ser humano. Criado para ser um ser em sociedade, não é possível compreender o homem como um ser solitário, isolado e indiferente aos outros com quem convive (ALMEIDA, 2016).

A partir dessa ideia, várias teorias foram elaboradas sobre a subjetividade humana envolvendo os sentimentos que perpassam essas relações sociais, esses convívios cotidianos. Dentro desse contexto, muitas categorias foram surgindo para as formas de relacionar-se e, dessa forma, quase tudo foi se encaixando dentro de um conceito.

Assim, nasceu o conceito para o que hoje chamamos de amor. Cerca de 380 anos a.C. Platão, em $O$ Banquete, já trazia sua reflexão sobre como se dá a forma de amar nos sujeitos. Retomando Sócrates, Platão traz em sua fala que o amor, quando a um objeto, só acontece quando ausente, ou seja, só se ama o que não se tem, e em caso de uma pessoa, só se ama o que não se é. Dentro desse contexto, já se tem historicamente um sofrimento embutido nos relacionamentos amorosos de uma forma geral.

Junto às relações humanas, foi se percebendo também o sofrimento humano motivado, e por vezes, em virtude da forma como tais relações são vivenciadas e, em alguns casos mais agravados, o adoecimento psíquico. O sofrimento é inerente à condição humana, o que resta saber aqui seria em que ponto tal sofrimento deixa a condição natural humana e passa à condição de doença (MINKOWSKI, 2000).

O próprio amor já seria um sintoma neurótico (MACEDO, 1998). Então já se teria aqui uma nova discussão, na qual não seria a forma de relacionar-se a causa do problema psíquico, mas sim mais um dos sintomas.

Levando em consideração o contexto sociocultural no qual os sujeitos encontram-se integrados, e tomando como fundamento as teorias desenvolvidas por Bauman (2003) sobre a liquides das relações humanas, a lógica dos relacionamentos atuais está voltada para um uso imediato, o prazer passageiro, a satisfação espontânea, resultados que não exijam esforços prolongados. 
Tais relações seriam frutos de uma "sociedade hedonista", onde tudo o que retarda a satisfação é visto de forma inadequada, e o amor, o qual precisa de tempo, encontra-se nessa inadequação. Dessa forma, os "relacionamentos de bolso" escondem a insegurança e o medo das pessoas se envolverem, assim como a incapacidade de saírem da zona de conforto e perderem tempo com algo. Cada indivíduo tem o desejo de um amor que o satisfaça e que, por algum momento afaste a solidão, mas não quer ter que esforçar-se, nem mesmo por um momento, de ter consigo um peso que o impeça de flutuar (BAUMAN, 2003).

A saúde psíquica depende de até que ponto o sujeito consegue se entregar. Baseia-se na atitude não neurótica da capacidade do sujeito para o amor. Ele acredita que as enfermidades psíquicas são uma perturbação da capacidade natural de amar (REICH, 1975).

Durante o ano de 2015, a partir da vivência nos cenários de prática da Residência em Saúde Mental Coletiva, foi observada grande demanda de encaminhamentos para a psicoterapia no CAPS III de Iguatu, além de se observar também um número considerável de demanda do CAPS AD e, dentro dessa demanda, foi identificada a recorrência de grande número de questões envolvendo problemas afetivos, de relacionamentos amorosos, como sendo o foco do adoecimento psíquico, de acordo com a fala dos próprios usuários.

A partir dessa observação, surgiu o interesse em se falar mais sobre assunto, vista a importância de um relato de experiência dessa prática psicológica voltada para a problemática das relações amorosas fragilizadas, que colocam os sujeitos em situação de sofrimento afetivo, e se existe realmente ligação entre esses relacionamentos com o adoecimento psíquico e, uma vez que existem, até que ponto essa ligação é estabelecida.

O objetivo geral deste relato é apresentar a experiência clínica de psicoterapia voltada aos relacionamentos amorosos e o adoecimento mental no serviço de saúde mental do CAPS Ad e CAPS III no município de Iguatu-CE. A proposta é descrever a experiência clínica no acompanhamento de psicoterapia nos serviços de Saúde Mental do município de Iguatu; identificar se há relação entre os sintomas apresentados e os relacionamentos amorosos e examinar a partir da experiência no atendimento psicoterapêutico os relacionamentos amorosos e o adoecimento psíquico. 


\section{Relato de Experiência: uma Metodologia em humanas}

Quando se fala em pesquisa na área de humanas, especialmente nos setores que envolvem a subjetividade com todos os seus desdobramentos, a pesquisa qualitativa tem sido uma das grandes apostas para se alcançar a finalidade de captar a essência do assunto principal que se deseja estudar: o sujeito.

Partindo desse pressuposto, o Relato de Experiência vem surgindo como um aporte de grande valia dentro da pesquisa qualitativa, sendo capaz de enriquecer os pontos que se objetiva trabalhar, não deixando a desejar em critério metodológico, nem tampouco em fidedignidade.

Esta técnica tem sido utilizada frequentemente nas áreas da Antropologia, Ciências Sociais, Mercadologia e Educação em Saúde. Ela é apropriada nas pesquisas qualitativas, que objetivam explorar um foco, ou seja, um ponto em especial (RESSEL et al., 2008).

Apesar de não ter o objetivo de testar hipóteses, nem confirmar ou falsear teorias, o Relato de Experiência é a principal metodologia utilizada como meio para correlacionar os achados de realidade a partir da observação sistemática realizada e das bases teóricas pertinentes. O Relato traz a possibilidade de ser integrador de situações e vivências que tenham o merecimento de serem relatadas, cujas informações provoquem inquietações que em alguma medida facilitem uma ressignificação dos acontecimentos narrados e práticas futuras (DYNIEWICZ, 2009).

Para tanto, foram utilizadas para a coleta de dados e, posteriormente, análise dos resultados as Versões de Sentido dos atendimentos realizados, além da narração do percurso clínico desenvolvido ao longo de todo o período de acompanhamento psicoterapêutico nos serviços de Saúde Mental de Iguatu.

Primeiramente foi feita a construção da agenda e a separação dos turnos para atendimento individual. Em seguida foram selecionados aleatoriamente os usuários do serviço que seriam acompanhados em psicoterapia. Após realizados os primeiros atendimentos dos pacientes foi observada a demanda trazida por eles e identificada a de maior recorrência, a saber 11 no total, que foi a voltada aos problemas com relacionamentos amorosos, ou como um dos pacientes identificou em sua fala, "o problema é o amor" (sic). Ao final de cada atendimento desses onze identificados foi feita uma versão de sentido para o respectivo, constando as impressões mais marcantes. 
Sobre as Versões de Sentido, é possível descrevê-las como um instrumento de aspecto fenomenológico utilizado por algumas abordagens psicológicas para registro de acompanhamento psicoterapêutico, que pode ser utilizado posteriormente de diversas formas. Surgiu inicialmente para a supervisão de psicoterapeutas iniciantes e foi ganhando espaço dentro das abordagens humanistas da psicologia.

\footnotetext{
No fim de cada sessão de um atendimento terapêutico, imediatamente após seu término, escrevemos alguma coisa. Isso que escrevemos não pretende ser um relato do que aconteceu em sua materialidade, mas uma tentativa de dizer a experiência imediata do terapeuta enquanto pessoa naquele momento, e enquanto ainda referida à sessão que acaba de terminar (AMATUZZI, 2001).
}

As Versões de Sentido são descritas ainda como sendo tanto objetivas quanto subjetivas, uma vez que se tratam da experiência do terapeuta referida ao atendimento que acabou de realizar; é ao mesmo tempo um sentido capado e um sentido produzido: somente é percebido quando produzido como participante da relação terapêutica; pode se desdobrar em outros sentidos e em atos sucessivos de expressão; somente aparece quando o próprio ato de expressar fizer sentido para o terapeuta (AMATUZZI, 2001).

Assim, as Versões de Sentido não seriam o mesmo que um informe de sessão, nem teriam o mesmo objetivo da evolução de prontuários, pois não têm o caráter objetivo de informar, nem descrever o diálogo desenvolvido. Portanto, vai muito mais além do simples registro, busca transformar os atendimentos em algo com sentido, fazer emergir uma teorização sobre o vivido, permitindo uma visão mais aguda sobre o processo do paciente através da relação com o terapeuta (MOREIRA, 2001).

Após investigação cuidadosa das versões de sentido foram selecionadas as que tiveram maior relevância para o tema escolhido, visto que os próprios usuários escolheram tal temática ao trazê-la para o foco de sua terapia. Por fim, foi feito um apanhado do corpo teórico para compor o relato, auxiliando no embasamento das ideias e discussões trazidas a partir do relato da experiência vivenciada.

Vale ressaltar que o presente trabalho preconiza a garantia do sigilo ético que protege os usuários do serviço e está prevista na ética da prática profissional do psicólogo, o que justifica o relato da experiência e não dos atendimentos ou da história dos sujeitos. 


\section{Sobre as questões do amor e a experiência clínica}

No início do ano de 2015, mês de janeiro, a equipe de residentes da ênfase de Saúde Mental Coletiva, do programa de Residência Integrada em Saúde da Escola de Saúde Pública do Ceará, deu início às atividades no CAPS III no município de Iguatu, que é uma cidade de médio porte, com cerca de 100 mil habitantes, localizada na região centro-sul do estado do Ceará, ficando em torno de $390 \mathrm{~km}$ de distância da capital, Fortaleza. No que diz respeito à Saúde Mental, possui uma rede completa, sendo composta por CAPS III, CAPS AD, CAPS Infantil, Residência Terapêutica e Unidade de Acolhimento Infanto Juvenil.

O núcleo de psicologia ficou responsável por, dentre outras atividades previstas nos eixos temáticos propostos para a construção da agenda dos residentes, realizar acompanhamento psicoterapêutico, a fim de atender à demanda do serviço e contemplar o eixo da agenda destinado ao desenvolvimento de atividades envolvendo práticas clínicas.

Após os primeiros atendimentos psicológicos individuais ficou evidente uma grande demanda relacionada a problemas amorosos como sendo a "causa inicial" do problema psicológico. Grande parte dos usuários atendidos atribuiu seu sofrimento psíquico ao "amor", seja ele por questões de desentendimento/rompimento, de excesso ou de ausência (não conseguir se relacionar). De uma forma geral, eles relacionaram o surgimento dos primeiros sintomas a algum tipo de conflito afetivo em seus relacionamentos, ou à ausência de um envolvimento amoroso.

A partir do segundo semestre do mesmo ano, mês de agosto, uma vez realizado o rodízio nos equipamentos da Saúde Mental do município, as atividades passaram a ser desenvolvidas no CAPS AD. Este serviço também apresentou, por parte dos usuários, grande associação entre as questões problemáticas e as relações afetivas.

Alguns usuários chegaram a trazer ao conhecimento da equipe multiprofissional a existência de comunidades terapêuticas que incluem em seu programa de acompanhamento a abstinência sexual e privação de envolvimento amoroso durante um prazo determinado, pois acredita que a afetividade se constitui como uma das principais fragilidades do tratamento de alcoolismo e dependência química, no que diz respeito às recaídas.

Após delicada escuta de cada um desses sujeitos, os quais trouxeram a questão amorosa como foco principal para ser trabalhado nos atendimentos, surgiram algumas 
semelhanças em seus processos terapêuticos e é a partir da narração descritiva de tais semelhanças que se constitui essa experiência clínica. Portanto, as peculiaridades de cada caso, suas diferenças e idiossincrasias não se fazem relevantes aqui.

Vale ressaltar ainda que não se busca defender abordagens psicológicas, ou paradigmas epistemológicos neste relato, e sim oferecer uma ampla visão em diversos campos teóricos para enriquecer a temática apresentada e reafirmar que não se trata apenas de uma suposição de determinada prática profissional, mas de um olhar integral ao sujeito a partir da experiência vivida.

De início, não cabe julgar se há realmente tal ligação que torne coeso os discursos desses usuários, pois o que importa realmente é que, para eles, existe a ligação entre o sofrimento vivido e algum tipo de experiência traumática sofrida no que diz respeito às suas formas de se relacionar com o "amor". Vale ressaltar que, neste ponto, o conceito de amor utilizado é o do senso comum, é o que os sujeitos ouvidos acreditam que seja o amor e, por sua vez, denominam dessa forma.

Ao longo das sessões, no entanto, foi possível observar que, mesmo antes da experiência amorosa, os sujeitos já apresentavam algum tipo de desfuncionalidade afetiva em suas interações. As formas de se relacionar, de uma maneira geral, já começaram a apresentar alguns sinais, que se expuseram mais intensamente ao alcançar a esfera amorosa.

Dentro desse contexto, se pode afirmar que a dor é suportável e até mesmo despercebida, até que chegue à dimensão dos afetos. É recorrente encontrar no discurso dos sujeitos o outro como sendo o suporte responsável por retroalimentar seus egos, suas neuroses e sua condição de sofrimento.

Quando existe a insatisfação, mas esta é suportável, o desejo continua ativo e o sistema psíquico continua estável. Se, ao contrário, a insatisfação é desmedida, o desejo perde seu eixo e a dor aparece (NASIO, 1997).

\footnotetext{
(...)Entretanto, como aceitar que o meu parceiro possa ter essa função castradora de limitar a minha satisfação? Sem dúvida, esse papel restritivo do ser amado pode ser desconcertante, porque habitualmente atribuímos ao nosso parceiro o poder de satisfazer os nossos desejos e nos dar prazer. Vivemos a ilusão, em parte verificada, de que ele nos dá mais do que no priva (NASIO, 1997).
}

Ele afirma ainda que ao perder a pessoa do ser amado, se perde uma das fontes que alimenta a força do desejo, sem com isso perder a força que perdura, indestrutível e inesgotável 
enquanto existe vida. Se perde também a silhueta que, como um apoio, refletia as imagens do espelho interior do sujeito e, principalmente, se perde o ritmo sob qual vibra a força vital do desejo. Em resumo, perde-se o ser amado, uma fonte de alimento, o objeto das projeções imaginárias do sujeito e o ritmo do desejo. Esse processo, inevitavelmente, leva à perda da coesão e da textura de uma fantasia indispensável à estrutura do ser humano.

O resultado disso é o surgimento da dor, o sofrimento afetivo que gera o adoecimento psíquico. A lesão provocada pela dor psíquica não está no desaparecimento físico do ser amado, mas no transtorno interno gerado pela desarticulação da fantasia do amado. "O que dói não é perder o ser amado, mas continuar a amá-lo mais do que nunca, mesmo sabendo-o irremediavelmente perdido. "(NASIO, 1997)

Logo, ao ouvir um relato sobre o quanto o amor pode ser adoecedor, o que se está ouvindo na realidade é a narração sobre o quanto os sujeitos se percebem adoecidos quando lhes falta o suporte amoroso.

O eu é como um espelho em que se refletem as imagens de partes do nosso corpo ou aspectos do nosso amado. Um excesso de investimento de uma dessas imagens significa amor se a imagem se apoia sobre a coisa real da qual ela é reflexo. Em contrapartida, o mesmo excesso de investimento significa dor se o suporte real nos deixou (NASIO, 1997).

Foi observada que intimamente ligada às questões amorosas estavam as questões sexuais. Comumente, quando um usuário trazia a questão amorosa para o foco da terapia, trazia junto a ela alguma questão voltada para a vivência de sua sexualidade. Não necessariamente problemas com o ato sexual propriamente dito, ou envolvendo o prazer genital, mas algum conflito ligado a maneira de experienciar sua sexualidade.

O que foi percebido nos relatos ao longo dos atendimentos foi que existem contingências socioculturais perpassando todos os momentos da vida dos sujeitos e, algumas vezes, o fato de não conseguir enfrentar tais contingências os fez criar alguns ajustes criativos, que acabaram por interferir diretamente na expressão de sua sexualidade.

A partir da experiência clínica se pôde notar que o meio se mostrou como fator determinante, seja por reprimir ou por liberar em demasia. O resultado disso foi a desorientação do paciente sobre sua forma ideal de experimentar seus impulsos sexuais e, consequentemente, seus afetos. 
Reich (1975) fala sobre uma "hipocrisia sexual”, que seria a responsável pela orientação dos sujeitos de alguma forma. As ideias sexuais ficam reprimidas por não serem admitidas pelo meio e, então, não se pode viver plenamente os instintos. Dentro desse conceito ele incluiu todos os comportamentos sexuais socialmente inaceitáveis, ou ainda que aceitos, estigmatizados.

Ao sujeito, cabe conservar essa hipocrisia sexual e lidar com seus afetos, uma vez que a vivência da sexualidade reprimida também poderá leva-lo a algum tipo de desordem afetiva, pois o fará se sentir estranho no mundo. Portanto, Volpi (2005) defende que permitir-se experimentar ou não os impulsos sexuais e a forma de fazê-lo se configura como chave para o surgimento dos sintomas psicóticos e das neuroses.

Assim, é possível afirmar que o modo de se lidar com a própria sexualidade afeta as formas de amar, que em última análise, interfere em vários modos de se relacionar, não apenas amorosamente, mas com o todo social, o qual oferece o suporte necessário para enfrentamento das diversas situações problemáticas do ser.

\begin{abstract}
A sexualidade faz parte de nossa conduta. Ela faz parte da liberdade em nosso usufruto deste mundo. A sexualidade é algo que nós mesmos criamos - ela é nossa própria criação, ou melhor, ela não é a descoberta de um aspecto secreto de nosso desejo. Nós devemos compreender que, com nossos desejos, através deles, se instauram novas formas de relações, novas formas de amor e novas formas de criação. O sexo não é uma fatalidade; ele é uma possibilidade de aceder a uma vida criativa (FOUCAULT, 1984).
\end{abstract}

Há outros teóricos que defendem também que o papel do sexo não foi acidental, nem tampouco casual (NASIO, 1997). Das muitas tendências, inclinações e propensões naturais dos seres humanos, o desejo sexual é a mais incontestavelmente social. Ela se estende na direção de outro ser humano, exige sua presença e se esforça para transformar em união essa presença. O ser humano anseia por convívio, por se tornar menos incompleto e insatisfeito, unindo-se um ao outro.

Nesse ponto, ficou evidente o quanto o meio de convívio pode ser influente na construção subjetiva da afetividade, como isso traz repercussão nas maneiras de se relacionar e o quanto tentar lidar com essa influência pode provocar sofrimento (FOUCAULT, 1975). O discurso das pessoas acompanhadas retorna diversas vezes a esse mesmo ponto e, avança em direção ao adoecimento já existente e ao sofrimento provocado pelos sintomas até a percepção de um transtorno mental ou do uso problemático de algum tipo de substância. 
Vale ressaltar que o sofrimento em si, seja motivado por qual situação for, não foi o único aspecto necessário para o adoecimento desses usuários, pois ele é inerente à própria condição humana (MINKOWSKI, 2000). Porém, foi percebida certa intolerância em relação ao sofrimento e associando-o aos conflitos vividos na dimensão do amor, independentemente da ordem cronológica dos fatos.

Em outras palavras, em geral, não foi necessário o conflito vivenciado no amor para causar o sofrimento e posterior adoecimento psíquico, no entanto, a forma - conflituosa ou não - de se relacionar com o outro, desde o princípio das histórias ouvidas, foi fator determinante para gerar todo quadro se seguiu.

As relações atuais estão cada vez mais tóxicas por causa do próprio contexto que se vive atualmente de uma forma geral, no qual todas as coisas são por demais efêmeras e, por isso, necessitam de uma satisfação imediata. O amor demanda tempo, sendo que esse tempo é, principalmente, o que não há mais disponível para ser oferecido, o que tem tornado as pessoas cada vez mais descartáveis (BAUMAN, 2003).

Identificou-se nos usuários o sofrimento acompanhado por sentimentos de frustação, uma vez que não sentiam suas expectativas serem correspondidas pelos seus pares. Era como se o parceiro tivesse a responsabilidade de sanar todas as suas necessidades afetivas, subestimando os afetos e expectativas também presentes neste parceiro. Então, a incapacidade de lidar com a frustração, trouxe à consciência todas as outras questões às quais ele não se sentia capaz de lidar sozinho, aumentando sua dor.

Se você investe numa relação, o lucro esperado é, em primeiro lugar e acima de tudo, a segurança - em muitos sentidos: a proximidade da mão amiga quando você mais precisa dela, o socorro na aflição, a companhia na solidão, o apoio para sair de uma dificuldade, o consolo na derrota e o aplauso na vitória; e também a gratificação que nos toma imediatamente quando nos livramos de uma necessidade (...) Você busca o relacionamento na expectativa de mitigar que infestou sua solidão; mas o tratamento só faz expandir os sintomas, e agora você talvez se sinta mais inseguro do que antes, ainda que essa "nova e agravada" insegurança provenha de outras paragens (BAUMAN, 2003).

Assim, foi possível encontrar nesses acompanhamentos clínicos uma ligação entre os relacionamentos amorosos e o adoecimento psíquico, trazida pelo próprio sujeito, falando de suas angústias e buscando trabalhar-se, não apenas nessas, mas em todas as suas relações, para lidar com o seu sofrimento e sair do quadro de adoecimento. 
A questão final no acompanhamento desses usuários foi a capacidade de lidar com a dor, pois embora ela tenha se apresentado mais intensamente em relação aos conflitos afetivos vivido, ela pode surgir no desenrolar de qualquer outra situação ao longo vida.

Tal experiência foi tão enriquecedora quanto gratificante, uma vez que essa discussão raramente é trazida na prática da psicologia clínica, embora muito debatida por vários teóricos das mais diferentes abordagens por toda a parte.

\section{Considerações Finais}

A inclusão de discursões sobre essa temática dentro dos serviços de saúde mental é capaz de ressignificar as práticas profissionais no atendimento aos usuários, construindo novos saberes, aperfeiçoando os já existentes e adaptando às particularidades de cada caso.

Existe um saber comum sobre a ligação dos afetos, do sofrimento humano e o adoecimento psíquico, mas pouco é discutido sobre isso nas práticas cotidianas. A partir deste relato de experiência foi possível examinar melhor essas questões e sua repercussão na vida dos usuários acompanhados por esses serviços.

É perceptível a influência dessas relações na evolução ou no comprometimento do processo terapêutico, a depender de como acontece seu desenrolar. Os laços amorosos ocupam grande espaço na área afetiva dos sujeitos e são capazes interferir de diversos modos, como foi possível constatar.

Ao examinar essa experiência clínica vivida, se pôde constatar que o assunto deve ser trabalhado com o mesmo esmero com o qual o usuário o aborda. Há bastante investimento afetivo por parte desses sujeitos em suas relações e, ao profissional responsável, cabe também um investimento maior para se apropriar dessas demandas e conseguir contemplá-las de forma mais incisiva.

Não se trata aqui de explicar causas e suas consequências, utilizar-se de conceitos teóricos e aplica-los ao longo do acompanhamento terapêutico, mas de, a partir da consciência de que há uma grande relevância desses aspectos para o processo vivenciado, conseguir compreender melhor aquele sujeito que se expõe na prática clínica e busca, de alguma maneira, alcançar o seu equilíbrio. 
"Assim o amor permanece um mistério impenetrável, que não se deve explicar, mas apenas constatar" (BAUMAN, 2003).

\section{Referências}

ALMEIDA, J.F.; A Solidão Terapêutica Nos Devaneios De Um Caminhante Solitário De Jean-Jacques Rousseau. Kínesis, Vol. VIII, n. 16, p.83-95, 2016.

AMATUZZI, MM. Versão de sentido. In: Por uma psicologia humana; 73-86. Campinas: Alínea, 2001.

BAUMAN, Z. Amor Líquido - Sobre a Fragilidade dos Laços Humanos. Rio de Janeiro: Zahar, 2003.

DYNIEWICZ, AM. Metodologia da pesquisa em saúde para iniciantes. São Caetano do Sul, SP: Difusão Editora, 2009.

FOUCAULT, M. Doença Mental e Psicologia. Rio de Janeiro: Tempo Brasileiro, 1975.

FOUCAULT, M. Sexo, Poder e Política de Identidade. In: The Advocate, 7 de agosto de 1984; 26-30 e 58. Trad. Wanderson Flor do Nascimento.

MACEDO, GM. O Amor é um sintoma neurótico. University of Manchester. Reino Unido, 1998.

MINKOWSKI, E. Breves reflexões a respeito do sofrimento (aspecto pático da existência). Rev. latinoam. psicopatol. fundam., São Paulo, v. 3, n. 4, p. 156-164, 2000.

MOREIRA, V. Más allá de la persona: hacia una psicoterapia fenomenológica mundana. Santiago: Editorial de la Universidad de Santiago de Chile, 2001.

NASIO, JD. O Livro da Dor e do Amor. Rio de Janeiro: Zahar, 1997.

REICH, W. A Função do Orgasmo-problemas econômico-sexuais da energia biológica. São Paulo: Brasiliense, 1975.

RESSEL, L.B. et al. O uso do grupo focal em pesquisa qualitativa. Texto contexto - enferm., Florianópolis, v. 17, n. 4, p. 779-786, 2008. DOI: http://dx.doi.org/10.1590/S0104-07072008000400021

VOLPI, JH. Reich e a economia sexual. Curitiba: Centro Reichiano, 2005.

\section{Como citar este artigo (Formato ABNT):}

SILVA FILHO, José Adelmo da; MOREIRA, Lumara Alves; HOLANDA, Maria do Livramento Alencar de. Uma Abordagem sobre os Relacionamentos Amorosos e o Adoecimento Psíquico: Relato de Experiência. Id on Line Rev.Mult. Psic., 2018, vol.12, n.41, p.789-800. ISSN: 1981-1179.

Recebido: 11/06/2018

Aceito 19/07/2018 